\title{
The Importance of Models in Sociology: The Example of Max Weber
}

\author{
Albertina Oliverio \\ Department of Law and Social Sciences, Università Degli Studi G. D’Annunzio-Chieti-Pescara, Chieti, Italy \\ Email: albertina.oliverio@unich.it
}

How to cite this paper: Oliverio, A. (2020). The Importance of Models in Sociology: The Example of Max Weber. Advances in Applied Sociology, 10, 1-10. https://doi.org/10.4236/aasoci.2020.101001

Received: December 7, 2019

Accepted: December 23, 2019

Published: December 26, 2019

Copyright (C 2020 by author(s) and Scientific Research Publishing Inc. This work is licensed under the Creative Commons Attribution International License (CC BY 4.0).

http://creativecommons.org/licenses/by/4.0/

\begin{abstract}
Sociological research method may be resumed by three concepts of Karl R. Popper, "problems-theories-critics". Within this field, the role of theoretical models is central. In particular, the concept of model is comparable to the one of ideal type conceived by Max Weber. As a matter of fact, Weberian ideal type is still one of the most popular methodological instruments in social sciences. Conceived as a non-normative form of conceptualization finalized to simplify and reduce external social world complexity, ideal type allows the organization of an increasing knowledge acquaintance. It is shown that as a significant character of understanding sociology, ideal type is founded on an individualistic and nomological epistemological substrate. Conceived in these terms, it is argued that ideal type is therefore the expression of a unique method of explanation which can be traced in some examples showing how models construction is one of sociology's most used instruments.
\end{abstract}

\section{Keywords}

Sociological Models, Ideal Type, Objectivity

\section{Introduction}

According to Karl R. Popper (1963), every research activity involves three fundamental steps: the formulation of problems, the elaboration of theories to solve them, and the verification of the theories through critical activity. Similarly to other disciplines, in sociology, a research always starts with a problem or a question concerning social reality. For example: which factors favor delinquency? What are the characteristic traits of juvenile gangs in large cities? Are the new social media a reason for the growing isolation of individuals? What are the typical internal dynamics of immigrant communities?

After formulating the problem, a theory must be elaborated and then checked 
through an articulated process based on various steps, including the identification of the proper unit of analysis (global societies, social classes, groups, institutions, individuals), the best approach to the problem, and the methods and techniques to be used for collecting, organizing, describing and interpreting data. Moreover, collecting data, in particular, is an essential aspect of sociological research. Since the early nineteenth century, the pioneers of empirical sociology in France, Germany and England, carried out great social studies on the living conditions of the lower classes and industrial workers, evidencing disastrous hygiene and health levels. In the United States, the first sociologists focused instead on European and Asiatic immigrants in popular neighborhoods. Using various sources (stories, autobiographies, personal letters, the archives of migrant organizations, etc.) the scholars of the Chicago School were able to produce a detailed and accurate description of the ethnic groups that migrated to the US in the early twentieth century (family structure, marriage, social hierarchies, religious orientation, personal interests, etc.).

This wealth of information was then organized by sociologists in concepts, ideal types, models, typologies. For example, in his 1920s study, William Thomas (1966) identified three types of immigrant based on their personality: the "philistines" (rigid personalities, norm followers, resistant to change), the "bohemians" (instable personalities, mutable characters, easily influenced) and the "creatives" (structured characters but open to change). Although obviously simplifying, these types had the merit of identifying factors of stasis and change within those groups.

The concepts, the models, the categories used to interpret, i.e. to describe and explain the data collected in a research are the sociologists' toolbox: they allow them to distinguish and classify types of family (nuclear, extended, single-parent, recombined, etc.), of power (traditional, charismatic, bureaucratic), of teaching styles (authoritarian, democratic, lax), of organizations (administration, small artisanal business, industrial business), of culture, religion and so on.

Only with the help of suitable categorizations it is possible to impose an order on the content of the investigated reality. Indeed according to some, without these classifying structures any advanced form of conceptualization, reasoning, language, data analysis, or research would be impossible (Bailey, 1994). Models have both a descriptive and explicatory function. From a descriptive point of view, they offer a simplified version of the main traits of a phenomenon, eliminating irrelevant details; from an explicatory point of view, they show the relations among the elements of that phenomenon. From this perspective, Max Weber's "ideal type" acquires a central role in the methodology of social research. As a matter of fact, in what follows it is shown that ideal type allows the organization of an increasing knowledge acquaintance and that it is the expression of a unique method of explanation which can be traced in some examples showing how models construction is one of sociology's most used instruments. 


\section{Weber's Methodology and the Origin and Functions of the Ideal Type Model}

According to Weber, historical and social disciplines must be based on a method that is at the same time "individualistic" and "nomological". First of all, historical-social phenomena must be explained as the intentional and, above all, unintentional effects of specific causes, namely the behavior of individuals. For Weber, to explain a historical-social phenomenon it is necessary to reconstruct the logic that governs the underlying individual actions. But what does Weber mean by "reconstructing the logic of individual actions"? For Weber as for Georg Simmel, and for Karl Popper after them, it means "understanding" those actions, but not in the sense used by Wilhelm Dilthey in his later work (Eliaeson, 2000), but rather in the sense of highlighting the reasons behind them. The explanation of historical-social phenomena is closely related to the identification and understanding of their causes, that is, the reasons behind individual behaviors that in a given moment contribute to generating those phenomena (Weber, 1978).

Fundamentally, Weber founds the understanding and explanation of human actions on the principle of rationality, that is, on the formulation of hypotheses concerning the reasons that individuals may have had for acting in a certain way. It is precisely the analysis of these reasons that implies that these actions should be viewed as efforts to solve problems and are, as such, rational. This implies that understanding cannot be an act of immediate intuition but must be based on the formulation of interpretative hypotheses and their empirical verification. In general, the reconstruction of the logic underlying individual actions must be compatible with all the facts constituting the situation in which those actions took place.

Social scientists use the appropriate nomological knowledge and, by combining it with a rigorous situational analysis, produce a rational causal reconstruction of the actions and of their intentional and unintentional consequences. These ideal typical models of particular historical-social phenomena are reconstructions whose understanding is often essential for the identification of a connection between the actions and a given event. In other words, the researcher identifies the objective possibilities of causal imputation between the phenomenon he's studying and causally "adequate" conditions. Ideal types are in practice pure constructs of causal relations that the researcher conceives as objectively probable and causally adequate on the strength of his nomological knowledge, while assuming an "active" role in the rational interpretative process.

Thus for Weber, along with the individualist methodology, the "causal explanation" of specific cultural phenomena is also a necessary condition to ensure the scientific soundness of historical-social research, insofar as it makes possible the empirical identification of cause and effect relations, and therefore the verification of the hypotheses formulated by the researcher. In other words, the nomological theoretical apparatus goes hand in hand with the historical-social knowledge. On the other hand, in the context of historical-social sciences, laws 
are often obvious, so what one must focus on is rather the empirical generalizations, causal rules derived from commonsense knowledge (laws and generalizations that are necessary to explain the concrete phenomena one studies using the heuristic instrument known as ideal type).

In his essay Objectivity in Social Science and Social Policy, Weber (2011) presents the ideal type as an abstract construction or "ideal" scheme (in the sense that it is not "real", it does not represent the directly observed experience in its totality). The ideal type has a "utopia" character obtained by conceptually emphasizing certain traits of reality in order to show in a "pure" form certain characteristics of that reality, which becomes an example of the ideal type itself. The ideal type never corresponds exactly to its empirical referent. Rather in provides a touchstone that allows one to describe its significant elements, to measure it and compare it (Aronovitch, 2011; Burger, 1976; Grønning, 2017; Lindbekk, 1992; Rogers, 1969; Schnapper, 1999). Basically, the ideal type is a model that, while distinct from its empirical referent, derives from it its constitutive elements and is used to highlight its significant aspects and evaluate its differences. In the study of economics, for example, the "pure and perfect" market (the one in which competition is completely free) is an ideal type, a model against which actual markets can be compared.

This "conceptual frame" is constructed by separating what is essential in the individual phenomenon from what is instead "accidental", i.e. irrelevant to the specific case, and in producing a conceptual model that will progressively approach the concrete individual phenomenon by selecting and combining its "characteristic" traits. This is a logical procedure that requires the identification of the present and absent elements in the studied phenomena (Cavalli, 1981). This procedure cannot reproduce reality but is the most adequate instrument science has to identify the connections that are relevant in terms of the values under consideration. Such a heuristic instrument can serve to "orient" the historical-social research in the phase of causal determination: the ideal type is not therefore a hypothesis, but something that orients the researcher in the formulation of hypotheses; it is a theoretical scheme which can be applied to empirical context and provide comprehensive explanations (Rosenberg, 2015).

The function of the ideal type is therefore that of understanding the specific significance of historical-social events through their individualized causal explanation. Weber specifies that what is significant does not naturally coincide with the domain of any law, nor does it coincide with it the more universally valid the law is. The relation between reality and the ideas of value that provide it with meaning, as well as the evidencing and ordering of the elements of reality thus identified from the perspective of their cultural meaning, corresponds to an entirely heterogeneous perspective compared to an analysis of reality on the basis of laws, and its organization in general concepts. Furthermore, based on the above, it is evident that any "objective" treatment of cultural processes, whose ideal purpose is the reducing of the empirical data to "laws" is pointless. At the 
same time, laws are necessary if one wishes to validly establish causal relations through ideal-typical concepts. While for the historian causal knowledge consists in imputing concrete effects to concrete causes, the valid imputation of an individual effect is not possible, in general, without a "nomological" knowledge, that is, without the knowledge of the regularities of causal connections. It is therefore essential to have a "nomological" knowledge of the way in which humans usually react to given situations. The knowledge of laws does not therefore coincide with the knowledge of historical-social reality but rather is one of the instruments used by researchers to obtain this knowledge. For Weber, it is therefore possible to arrive at an individual social-historical analysis through a general one, thus bypassing the methodological bridge which divides humanistic interpretation and causal explanation in historical and cultural studies (Ringer, 2000).

\section{On Some Famous Models of Sociological Research}

It has been pointed out both that the weberian ideal type model has frequently been dismissed as an outmoded concept irrelevant to contemporary problems in the social sciences (Burger, 1976; Giddens, 1976) and that many social scientists have often been confused and unable to use it (Swedberg, 2017). Nevertheless, the heuristic potential of the ideal type model which has made it popular both in historical-social sciences and in other disciplines, has also ensured it has been one of the most popular instruments in social research in general, and in sociology in particular, since it is methodologically adequate and logically consistent (Hekman, 1983; Lopreato \& Alston, 1970). This is the case, for example, of Werner Sombart's description of the bourgeois or Georg Simmel's description of the foreigner or the poor. In the history of sociology, many scholars have made use of models or adopted approaches similar to Weber's ideal-typical construction. Their analyses often result in the construction of dichotomous typologies, including many famous ones. In the following, I will consider a number of examples related to studies of historical-social phenomena and of their evolution, which are particularly interesting.

Consider Charles H. Cooley's (1910) distinction between "primary groups" and "secondary groups". Primary groups are characterized by small size, primary, i.e. intimate and long-lasting, relations, cultural similarities and mutual help. In these groups the "self" coincides, at least for some aspects, with the common life and goals of the group. Primary groups play an important role in the development of individual personality. Examples of primary groups are the family, childhood friendships, and neighbors. Secondary groups, instead, are organized in opposition to primary groups and are characterized by more formal interactions and shorter term relations. Communication has the purpose of obtaining personal advantages and members of the groups are held together only by their common goals.

Another famous dichotomous model is the one based on the contrast between "community" (Gemeinschaft) and "society" (Gesellschaft) elaborated by Ferdinand 
Tönnies (2002). For Tönnies, the "community" is "organic" in the sense that any form of confidential, intimate, exclusive relation is part of the common life. It is centered on immediate relations: among family members, firstly, as well as neighbors and friends. Relations are based on intimacy, habit, shared languages, common memories and experiences. The economic organization is also interpreted from a communitarian perspective and even when it is based on exchange, there continues to be a fraternal spirit of participation and reciprocal gift, in contrast with the desire to maximize personal interest. "Society" on the contrary is based on artificial, rational, conventional, "mechanic" relations. It is characterized by the separation and isolation of individuals and by tensions between them. Relations are based on interest and no one is willing to give or do something for others, if not in exchange for something of equal value. It is based on calculation, on utilitarian exchanges. This "society" is exemplified by "bourgeois" or "exchange society".

Tönnies used this dichotomy to evidence how the evolution from informal communities to modern formal and rational society did not necessarily involve positive changes. For Tönnies, advanced societies, in which life was dominated by the "cold intellect" had to pay a high cost for their material progress, consisting in an increase in individual dissatisfaction and the loss of authentic solidarity, which could be found only within communities, where life followed "the warm impulses of the heart".

There are many other similar examples in sociology. One could cite the theory of deviancy elaborated by Robert K. Merton (1968), which resulted in the wellknown means-ends typological construction (conformity, innovation, ritualism, renunciation, rebellion) or the theory of structural variables elaborated by Talcott Parsons (1991), used to explain social relations (articulated on the basis of a series of oppositions: particularism/universalism, commonness/specificity, inscription/acquisition, affectivity/affective neutrality, collective interests/individual interests. Also famous are the two ideal types of society elaborated by Émile Durkheim (1960), the ones based on "mechanical solidarity" and the ones based on "organic solidarity", a distinction that corresponds to the one between premodern traditional societies, characterized by low division of labor and a social cohesion based on strong collective values, and modern societies, characterized by a high division of labor, by social cohesion resulting from the complementarity of functions, by a weakening of collective conscience and by the growth of individualism.

It is worth turning again to Durkheim for what is one of the best known models in the history of sociology: the suicide model. In his Suicide, Durkheim (1951) analyzed the phenomenon of suicide in Europe using the statistics available at the time. The starting point of his study was the hypothesis that human phenomena are no different from natural ones and that the study of suicide could be carried out using the same method and same rigor used in natural sciences. The implication was that what appeared as a quintessentially individual 
act was actually the result of collective forces allowing researchers to explain geographical and temporal patterns. This then was the particularity of Durkheim's theory: variations in suicide rates could be mostly explained through social causes rather than psychological or psychopathological reasons. In particular, the phenomenon was related to socialization: the level of social integration, that is the extent to which the social group was able to incorporate the individual, and social regulation: the extent to which the social group regulated and harmonized the behavior of individuals.

Durkheim identified four "models" or "types" of suicide (egoistic, altruistic, anomic and fatalistic), suggesting that suicide was the result of a problem in the socialization process. "Egoistic suicide" results from an insufficient degree of social integration, from the weakness of the bond between individual and society and of the control exercised by the latter. More specifically, for Durkheim, weak social integration is the cause of alienation, loneliness, a sense of uselessness and isolation in regards to one's community. Social ties weaken or dissolve, individuals rely less and less on the group, and end up finding themselves in a condition of excessive individualism and separation from society, a condition that Durkheim calls, precisely, "egoism".

Since suicide originates from difficulties in the socialization process, then, for Durkheim, it can be explained in terms of the function of general groups (political society) or partial groups (religious communities, family, professional groups). It is therefore possible, for example, to establish a causal relation between suicide and an insufficient integration of individuals in the religious community. Analyzing empirical data for Europe, Durkheim noted for example that the suicide rate was higher among Protestants than Catholics. How could this difference be explained? For Durkheim, the answer lay in the nature of the two religions. The Catholic religious system is characterized by a more developed structure and hierarchy and a more rigid tradition, and very little individual autonomy in relation to faith. On the contrary, Protestant religion allows the faithful to have a direct relation with God and is characterized by a much higher degree of religious individualism. The higher suicide rate among Protestants is a consequence of the doctrine of free will that characterizes their religion and by the "collapses of traditional beliefs" from which it originates. In general, the more autonomy a religion leaves to individuals, the more it stays out of their lives, the less the social cohesion and vitality. It is therefore the greater integration of the faithful in the church that explains, in Durkheim's opinion, the lower suicide rate among Catholics.

The model of "altruistic suicide" also depends on social integration, but in this case we have, on the contrary, and excess of integration. Altruistic suicide occurs in those situations in which society and social groups overpower the individuals, in which collective conscience dominates over the individual one, and in which the individuals are so closely involved in their society and group that they willingly sacrifice their lives to them. For society to exert an influence leading to 
such an extreme act, the individual must have, according to Durkheim, a weak sense of self, and this is the condition he calls "altruism". Durkheim uses this ideal type to explain for example the willingness of European soldiers to engage in suicidal actions in war, a result of the altruism implicit in military culture. More in detail, for Durkheim, soldiers are educated to attribute a low value to their life compared to the good of the army so that they are ready to sacrifice it if so ordered. Even in time of peace, military discipline is such that soldiers must be ready to execute orders even when they do not understand them. Individualism and army spirit are therefore incompatible according to Durkheim: soldiers base their behavior on external principles, an essential quality of the altruistic state, and are closely controlled by the army which does not allow them any autonomy, and this makes it seem normal to sacrifice their life in the name of their membership in the military.

In his study, however, Durkheim found some empirical data that could be explained neither by the egoistic nor by the altruistic model. Rather it appeared the result of the incapacity of society to fully integrate individuals by extending to them its norms. The "anomic" suicide model was elaborated to account for these suicides. Its fundamental characteristic is the insufficient presence of the regulatory action of society, of its norms and rules. An economic crisis may for example disrupt previous balances and produce unemployment or an unequal distribution of wealth, and this may lead to an increase in anomic suicides. In such a crisis, individuals are forced to curb their needs, to make more sacrifices, to learn to make do with less. But getting used to this new life requires time and the new constraints may be difficult to accept. Individuals may be unable to adapt to the new conditions, or may find them intolerable.

\section{Conclusion}

The abundant use of models in sociology and the considerations developed above allow us to return to what is one of the main contributions of Weber's epistemology and methodology, namely the effort to introduce objective criteria in historical-social studies based on causal explanations of human actions through empirical studies. As it is known, for Weber such objectivity requires two ineludible methodological passages. The first is the identification of the criteria through which events are selected when reconstructing historical-social phenomena. The second, which is the focus of the present essay, is the development of generalizing conceptual procedures that make this process of causal imputation possible. Through the first passage, Weber ensures the objectivity of historical-social sciences thanks to their independence from value judgments. More specifically, for Weber it is necessary to distinguish between our empirical knowledge of "what is" and our normative knowledge of "what must be". Our opinion on the validity of value judgments is a "matter of faith" not of empirical knowledge.

Historical-social sciences are tied to "subjective" presuppositions insofar as they 
investigate the aspects of reality to which-even if in an indirect fashion-we attribute cultural meanings. Nevertheless, the knowledge that characterizes those remains purely causal in the same way of our knowledge of individual natural processes endowed with meaning and a qualitative character. According to Weber, historical-social sciences are both causal sciences and particular sciences. They are causal sciences insofar as their theses must rest on rigorous demonstrations. They are "particular" sciences insofar as their goal is to understand the reality of the life around us, the one in which they are located, in its specificity. For Weber, historical-social sciences and natural sciences share the same epistemological premise: the presupposition of the objectivity of the first is precisely the possibility of offering causal explanations and this, albeit with different modalities, is also what characterizes natural sciences.

It has therefore been shown that theory, and abstract models in particular, are necessary in historical-social sciences insofar as there is a hiatus irrationalis between the reality that is always concrete and individual on the one hand, and concepts and general on the other, which are produced by abstracting from what is individual. As a matter of fact, nomological thought is typical of both historical-social sciences and natural ones. What distinguishes them is the function of rules and general concepts. For the first they are a tool, for the second ones they are the ultimate goal. In regards to the goals of historical-social sciences, namely the explanation of events in their individuality, these rules and concepts play an essential instrumental role. The understanding of the individual is achieved through the general. But while for natural sciences, the more general the law is the greater its validity, for historical-social sciences the contrary is true: the more abstract they are the less they can serve for the causal imputation of individual phenomena. This diversity corresponds to a difference in structure. The main point that the paper wanted to underline is that, as already stated above, for Weber, historical-social sciences do not rely on universal and necessary laws, but on general concepts, "rules of experience", or regularities in empirically observable behaviors. These have a heuristic purpose and an abstract character insofar as they are, precisely "ideal types" that serve to help produce interpretations that are empirically valid insofar as the data are compared with a possible interpretation.

\section{Conflicts of Interest}

The author declares no conflicts of interest regarding the publication of this paper.

\section{References}

Aronovitch, H. (2011). Interpreting Weber's Ideal-Types. Philosophy of the Social Sciences, 42, 356-369. https://doi.org/10.1177/0048393111408779

Bailey, K. D. (1994). Typologies and Taxonomies. An Introduction to Classification Techniques. London: Sage. https://doi.org/10.4135/9781412986397

Burger, T. (1976). Max Weber's Theory of Concept Formation. History, Laws and Ideal 
Types. Durham, NC: Duke University Press.

Cavalli, A. (1981). La funzione dei tipi ideali e il rapporto tra conoscenza storica e sociologia. In P. Rossi (Ed.), Max Weber e l'analisi del mondo modern (pp. 27-52). Torino: Einaudi.

Cooley, C. H. (1910). Social Organization. A Study of the Larger Mind. New York: Charles Scribner's Sons. https://doi.org/10.1037/14788-000

Durkheim, E. (1951). Suicide. A Study in Sociology. New York: The Free Press.

Durkheim, E. (1960). The Division of Labor in Society. Glencoe, IL: The Free Press.

Eliaeson, S. (2000). Max Weber's Methodology: An Ideal-Type. Journal of the History of the Behavioral Sciences, 36, 241-263. https://doi.org/10.1002/1520-6696(200022)36:3<241::AID-JHBS3>3.0.CO;2-C

Giddens, A. (1976). New Rules of Sociological Method. New York: Basic Books.

Grønning, T. (2017). Ideal Type. In B. S. Turner, C. Kyung-Sup, C. Epstein, P. Kivisto, W. Outhwaite, \& J. M. Ryan (Eds.), The Wiley Blackwell Encyclopedia of Social Theory (pp. 1-2). London: Wiley Blackwell. https://doi.org/10.1002/9781118430873.est0670

Hekman, S. (1983). Weber, the Ideal Type, and Contemporary Social Theory. Notre Dame, IND: University of Notre Dame Press.

Lindbekk, T. (1992). The Weberian Ideal-Type: Development and Continuities. Acta Sociologica, 35, 285-297. https://doi.org/10.1177/000169939203500402

Lopreato, J., \& Alston, L. (1970). Ideal Types and the Idealization Strategy. American Sociological Review, 35, 88-96. https://doi.org/10.2307/2093855

Merton, R. K. (1968). Social Theory and Social Structure. New York: The Free Press.

Parsons, T. (1991). The Social System. London: Routledge.

Popper, K. R. (1963). Science: Problems, Aims, Responsabilities. Proceedings of the Federation of American Societies for Experimental Biology, 22, 961-962.

Ringer, F. (2000). Max Weber's Methodology. The Unification of the Cultural and Social Sciences. Cambridge, MA: Harvard University Press.

Rogers, R. E. (1969). Ideal Type Theory. New York: Philosophical Library.

Rosenberg, M. M. (2015). The Conceptual Articulation of the Reality of Life: Max Weber's Theoretical Constitution of Sociological Ideal Types. Journal of Classical Sociology, 16, 84-101. https://doi.org/10.1177/1468795X15574414

Schnapper, D. (1999). La compréhension sociologique. Démarche de l'analyse typologique. Paris: PUF.

Swedberg, R. (2017). How to Use Max Weber's Ideal Type in Sociological Analysis. Journal of Classical Sociology, 18, 181-196. https://doi.org/10.1177/1468795X17743643

Thomas, W. I. (1966). Analytical Types: Philistine, Bohemian, and Creative Man. In M. Janowitz (Ed.), W.I. Thomas on Social Organization and Social Responsibility (pp. 168-181). Chicago, IL: University of Chicago Press.

Tönnies, F. (2002). Community and Society. Mineola, NY: Dover Publications.

Weber, M. (1978). Economy and Society. An Outline of Interpretative Sociology. Berkeley and Los Angeles, CA: University of California Press.

Weber, M. (2011). Objectivity in Social Science and Social Policy. In M. Weber (Ed.), Methodology of Social Sciences (pp: 49-112). New York: Routledge. 